\title{
A rare cause of invasive fungal sinusitis-Pseudallescheria boydii
}

\author{
Varada Vaze $^{1}$, Rohan Bidaye ${ }^{1 *}$, Neelam Vaid ${ }^{1}$, Sanjay Vaid ${ }^{2}$ and Mahesh Bora ${ }^{1}$ \\ ${ }^{1}$ Department of ENT, K.E.M Hospital, Rasta Peth Pune, Maharashtra, India \\ ${ }^{2}$ Star Imaging \& Research Centre, Pune, India
}

\begin{abstract}
Acute invasive fungal sinusitis is a significant cause of morbidity and mortality especially in immunocompromised patients. The offending organism usually belongs to the classes Zygomycetes (Mucorspp) and Ascomycetes (Aspergillus spp). However, in the last few decades, Pseudallescheria boydii (P.boydii) has been emerging as an important human pathogen, particularly in immunocompromised hosts. ${ }^{[1]}$ Although $\mathrm{P}$ boydii resembles Aspergillus on pathologic examination, it is crucial to identify it as it is typically resistant to amphotericin B. Patients with P boydii sinusitis should generally be treated with a combination of surgery and antifungal therapy. This is particularly important in immunocompromised patients with fungal invasion because mortality among these patients is high.
\end{abstract}

Our case report highlights the importance of distinguishing P. boydii from Aspergillus in a diabetic patient with invasive fungal sinusitis to prevent irreversible complications of the disease along with a review of literature of similar cases.

\section{Introduction}

Pseudallescheria boydii (anamorph Scedosporium apiospermum) is a ubiquitous ascomycetous fungus that causes a wide array of human infections that can affect practically all the organs of the body [1-3]. It was first isolated by Siebenmann in the 1880s as a pathogen in the ear of a child with chronic otitis externa [4]. It is a filamentous fungi present in soil, sewage, and polluted waters. Disease states produced by this organism range from cutaneous to disseminated infections [5]. Sinusitis may present among immunocompetent as well as in immunocompromised patients [6]. Such presentation varies widely ranging from localized mucosal involvement to invasive infection that requires a combination of therapies. Aspergillus fumigatus is the most common species implicated in paranasal sinus infection, with other species being rarely reported [7]. Like Aspergillus species, P. boydii can grow saprobically inside poorly draining bronchi or paranasal sinuses without causing invasive disease. Immunosuppression constitutes a significant risk factor for the surge of invasive fungal infections. The clinical presentation and even the findings on cytopathology and histopathology of P.boydii species, Aspergillus species and other hyalohyphomycotic organisms are very similar [8]. One of the most typical features of this species, which is very rare in other pathogenic fungi, is its ability to develop sexual structures on routine culture media. It has been repeatedly demonstrated that $P$. boydii has low susceptibillity to traditional antifungal drugs including amphotericin $B$ [9]. In this article, we describe a case of $\mathrm{P}$ boydii invasive fungal sinusitis to highlight the importance of identification via culture to ensure effective pharmacotherapy.

\section{Case presentation}

A 60 year old male patient with type 1 diabetes mellitus presented to the hospital with history of left sided headache, left nasal blockage and swelling over the left cheek 4 months ago. He was admitted for these complaints at another hospital where he underwent endoscopic examination and biopsy revealed invasive aspergillosis. This was followed by endoscopic debridement and administration of intravenous amphotericin for a month. Ten days after discharge patient came to our OPD with complains of diplopia and loss of vision in the left eye. On examination the patient was conscious, well oriented and afebrile. Anterior rhinoscopy revealed the presence of bilateral black scabs. The left eye pupil was fixed and dilated with complete opthalmoplegia i.e. paralysis of the $3^{\text {rd }}, 4^{\text {th }} 5^{\text {th }}$ and $6^{\text {th }}$ cranial nerves. CT scan showed the presence of an enhancing soft tissue lesion involving the hard palate, alveolar process of maxilla and maxillary/ethmoid/ sphenoid sinuses on the left side with extension to the orbital apex, retrobulbar space and involvement of the optic nerve. The Meckel's cave on the left side and the inferior wall of the left orbit were also involved. Subsequent contrast enhanced MRI study did not reveal any dural involvement. With a provisional diagnosis of Invasive fungal sinusitis intravenous Amphotericin was restarted and the patient was scheduled for surgical excision. He underwent a total maxillectomy with orbital exenteration via an external approach. Operative findings showed mucosa with black discoloration within the nasal cavity, sinuses and involving the orbit extending lateral to the optic nerve. The specimen was sent for culture and histopathological examination. On microscopic examination with potassium hydroxide mount $(\mathrm{KOH})$, fungal elements were seen. Fungal culture was done in Sabouraud's dextrose agar (SDA) which after 48 hours showed, white cottony fluffy colonies at $37^{\circ} \mathrm{C}$. Microscopically, septate hyphae with conidiophores

Correspondence to: Rohan Bidaye, Department of ENT, K.E.M hospital, Rasta Peth Pune, Maharashtra, India, Tel: +91-7744866000; Email: dr.rohanbidaye@ gmail.com

Key words: invasive fungal sinusitis, Pseudallescheria boydii, Voriconazole

Received: November 17, 2017; Accepted: December 07, 2017; Published: December 12, 2017 
and oval conidia borne singly from tips were observed. Interestingly, bulbous swelling in between the septae i.e. "intercalaryconidia", were seen among the majority of the septate hyphae, which gave the clue to the final diagnosis. On histopathological examination, septate hyphae were found with granulomatous inflammation. The fungal isolate was identified as P.boydii from its characteristic microscopic and macroscopic morphology (Figure 1).

Based on these findings, the antifungal coverage was changed to Voriconazole ( $4 \mathrm{mg} / \mathrm{kg}$ i.v. 12 hourly). Nasal endoscopy performed a week after the surgery revealed a healing mucosa. The patient was discharged on Voriconazole (200 mg PO b.d.) for 3 months. Repeat MRI was done after 3 months which revealed a large left-sided postoperative defect with non-visualization of left maxillary sinus, left orbit, and intraorbital segment of the left optic nerve. There were no signs of any focal signal abnormality or enhancement and the intracanalicular and intracranial segment of the left optic nerve appeared normal. (Figure 2).

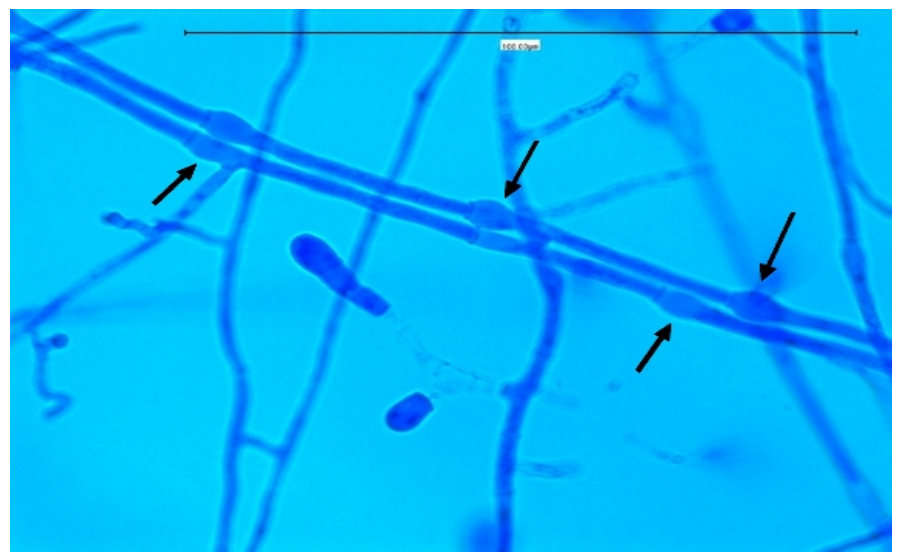

Figure 1. On staining: the main differentiating feature the Intercalaryconidia are marked by the black arrows.
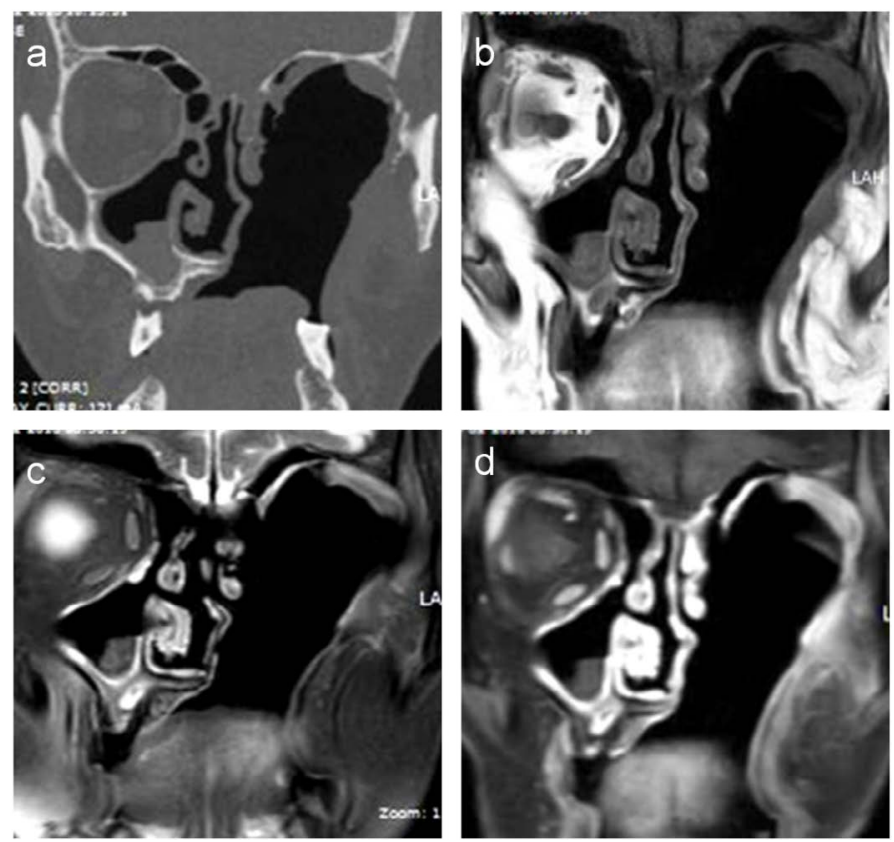

Figure 2. Coronal CT (a) $\mathrm{T} 1 \mathrm{~W}$ (b) and $\mathrm{T} 2 \mathrm{~W}$ (c) coronal MRI images reveal a large post-operative defect in the sinonasal/orbital region on the left side. Post-contrast fatsuppressed coronal MRI image (d) reveals faint enhancement of the mucosa lining the defect without evidence of any focal enhancing mass or any abnormal intracranial/ leptomeningeal enhancement.

\section{Discussion}

Aspergillus, Mucor and Candid species are the commonest pathogens causing fungal sinus infection. However, improvements in management of immunosuppressed condition have led to many emerging pathogens. Pseudallescheria boydii has been increasingly recognized as a pathogen in immunocompromised hosts with severe morbidity and mortality. Pseudallescheria boydii is known in literature by different names including Allescheria, Indiella americanus, Acremoniella lusii, Scedosporium apiospermum (asexual form). There is about a $77 \%$ incidence of mortality in immunocompromised hosts. The principal portal of entry in systemic disease is supposed to be the respiratory tract or cutaneous with possible widespread dissemination to other target organs. Till date 26 cases of sinusitis caused by $\mathrm{P}$ boydii have been reported across the world [7,10-34]. Our case brings the total number to 27. The male to female ratio was 0.58:1 (Table 1). Among the 27 cases, the maxillary sinuses were involved in 16 cases, the sphenoid sinuses in 14 , the ethmoid sinuses in 9 , the frontal sinuses in 2 , and the nasal cavity only in 1 (Figure 3 ). Of the 27 cases, mucosal invasion by fungal organisms was proven or suspected in 13 patients. There was no invasion in 9 patients and unknown in the remaining 5 patients (Figure 4). Of the 13 patients with proven or suspected invasive disease, 9 were immunocompromised. Four of these had leukemia, 3 were diabetics, and 2 had acquired immunodeficiency syndrome (AIDS) (Figure 5). Six of these 9 immunocompromised patients with mucosal invasion patients were treated with surgery and antifungal therapy, 1 was treated with surgery and antibacterial therapy and 2 were treated with antifungal therapy alone. Of the 4 immunocompetent patients with proven or suspected invasive disease, 2 experienced a complete resolution after undergoing combined surgery and/or antifungal therapy. One patient responded completely to surgery while the other died cause of the infection even after combined surgery and antifungal therapy. Five of the 9 patients without evidence invasion were immunocompetent, and all 5 experienced a complete resolution of their infection. Four of these were treated with surgery alone and the other with a combination of surgery and antifungal therapy. Of the 4 patients without signs of invasion who were immunocompromised ( 1 case each of adrenocortical insufficiency, sickle cell anemia, diabetes, and organ transplantation), 1 patient experienced a full resolution with combined surgery and antifungal therapy, 1 recovered completely with surgery alone, 1 died of squamous cell carcinoma of the sinuses following surgery, and the outcome of the other patient, who had undergone surgery, was not reported. Among the 5 patients in whom the presence or absence of fungal invasion was not reported, 2 were immunosuppressed while 3 were immunocompetent. Of the 2 immunosuppresed, the diabetic patient was treated with surgery alone and his outcome was not reported, and the post-transplant patient underwent combined surgery and antifungal therapy but died of a related cause. Of the 3 immunocompetent patients, all experienced a complete resolution of symptoms in which 2 were treated with surgery alone, and 1 patient had combined surgery and antifungal therapy (Table 2). This data suggests that the prognosis of immunocompetent patients is much better than immunosuppressed patients. Mimicking the clinical and histologic features of invasive aspergillosis, infections due to these pathogens are often resistant to conventional amphotericin B. $85 \%$ of the isolates in immunocompromised hosts were resistant to amphotericin. This can be problematic because amphotericin $B$ is often the first-line pharmacologic therapy for suspected invasive fungal sinusitis. In immunocompetent hosts sinusitis due to P.boydii is usually allergic and not infectious. There is no data to support the use of antifungals in allergic P.boydii sinusitis. 
Table 1. Male and female distribution of disease.

\begin{tabular}{|c|c|c|c|}
\hline Total number of patients (20-85 yrs) & Male & Female \\
\hline 27 & $10(37 \%)$ & $17(63 \%)$ & $0.58: 1$ \\
\hline
\end{tabular}

Table 2. Treatment given to patients with P.Boydi.

\begin{tabular}{|l|c|c|c|c|}
\hline Patients & $\begin{array}{c}\text { Patients treated with } \\
\text { surgery and antifungal } \\
\text { therapy }\end{array}$ & Antifungal therapy alone & Surgery alone & Other means \\
\hline $\begin{array}{l}\text { Immunocompromised pts with proven } \\
\text { invasive disease }\end{array}$ & $6(66.66 \%)$ & $2(22.22 \%)$ & 0 \\
\hline $\begin{array}{l}\text { Immunocompetent patients with proven } \\
\text { invasive disease }\end{array}$ & $3(75 \%)$ & 0 & $1(25 \%)$ \\
\hline $\begin{array}{l}\text { Immunocompetent patients without evidence } \\
\text { invasive disease }\end{array}$ & $1(20 \%)$ & 0 & $4(80 \%)$ \\
\hline $\begin{array}{l}\text { Immunocompromised patients without } \\
\text { invasive disease }\end{array}$ & $1(25 \%)$ & 0 & $3(75 \%)$ \\
\hline $\begin{array}{l}\text { Immunocompetent patients with unknown } \\
\text { status }\end{array}$ & $1(33.3 \%)$ & 0 & 0 \\
\hline $\begin{array}{l}\text { Immunocompromised patients with unknown } \\
\text { status }\end{array}$ & $1(50 \%)$ & $\mathbf{5}$ & $2(66.7 \%)$ \\
\hline
\end{tabular}

Disease distribution amongst sinuses and nose

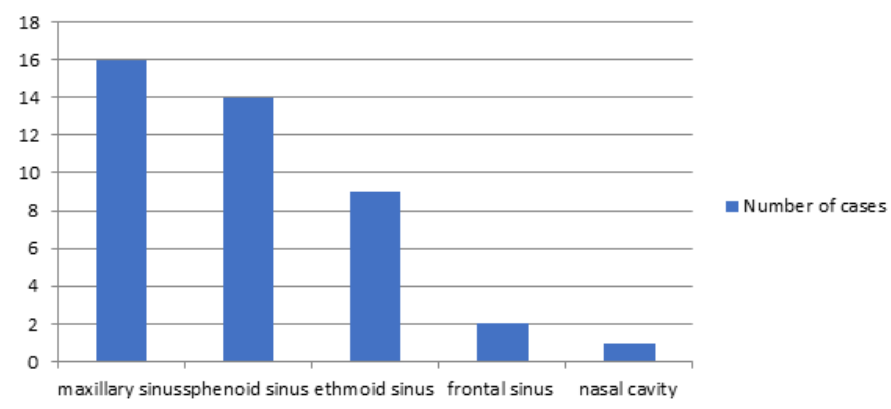

Figure 3. Distribution of disease amongst sinuses.

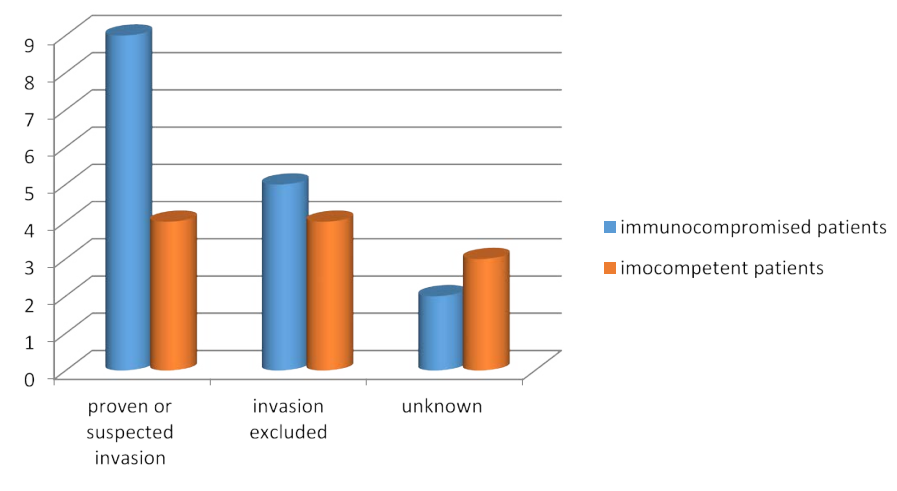

Figure 4. Mucosal invasion in patients infected with $P$. boydii.

\section{Proven or suspected invasive disease}

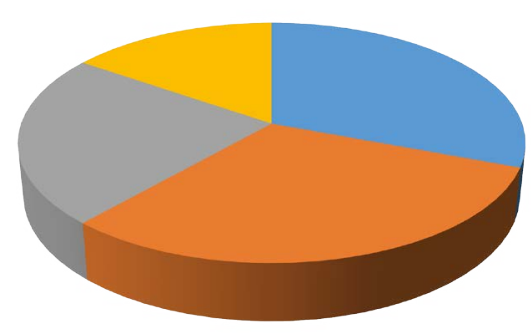

Immunocompetent pts

Immunocompromised pts with Leukemia

Immunocompromised pts with Diabetes melitus

Immunocompromised pts with AIDS

Figure 5. Immunity status amongst patients with invasive disease with $P$. Boydi.
As of now there are no recommended guidelines for the treatment of this pathogen but most experts feel that voriconazole is the drug of choice for p.boydii invasive sinusitis along with surgical debridement. Voriconazole has shown efficacy both in animal models [34] and in the clinical setting [35]. The dose is 200-300 mg twice daily for 6-12 months guided by clinical resolution and serial imaging [36]. As per literature $66.67 \%$ of patients with immunocompromised status with invasive disease were treated with surgery and antifungal therapy and $22.22 \%$ were treated with antifungal therapy alone. $75 \%$ of immunocompetent patients with invasive disease were treated with combination therapy while the remaining were treated with surgery alone.

Thus combination therapy of surgery and antifungal drugs, particularly in those patients with immunosuppression and fungal invasion is the preferred mode of treatment after confirmation of diagnosis with culture. This case report highlights the importance of culture and a definitive identification of the organism for selecting adequate pharmacologic therapy and further treatment.

\section{Acknowledgement}

The authors would like to acknowledge Mr. Rishabh Vaid, SKN Medical College, Pune for his help in literature review and manuscript editing.

\section{References}

1. Guarro J, Kantarcioglu AS, Horré R, Rodriguez-Tudela JL, Cuenca Estrella M, et al (2006) Scedosporium apiospermum: changing clinical spectrum of a therapy-refractory opportunist. Med. Mycol 44: 295-327. [Crossref]

2. Bates DD, Mims JW (2006) Invasive fungal sinusitis caused by Pseudallescheria boydii: case report and literature review. Ear Nose Throat J 85: 729-737. [Crossref]

3. De Hoog GS, Guarro J, Gené J, Figueras MJ (2000) Atlas of clinical fungi. ( $2^{\text {nd }}$ edn), Centraalbureau voor Schimmelcultures, Utrecht, The Netherlands, and University Rovira i Virgili, Reus, Spain.

4. Siebenmann F (1889) Die Schimmelmykosen des menschlichen Ohnes. Wiesbaden, Germany: Bergmann. pp: 95.

5. Green Wo Jr, Adams TE (1964) Mycetoma in the united states; a review and report of seven additional cases. Am J Clin Pathol 42: 75-91. [Crossref]

6. Guez S, Calas V, Couprie B, Stoll D, Cabanieu G (1992) Apropos of 2 cases of Scedosporium apiospermum nasosinusal infection. Rev Med Interne 13: 145-148. [Crossref]

7. Castiglioni B, Sutton DA, Rinaldi MG, Fung J, Kusne S (2002) Pseudallescheria boydi (Anamorph Scedosporium apiospermum). Infection in solid organ transplant recipients in a tertiary medical center and review of the literature. Medicine (Baltimore) 81: 333348. [Crossref] 
8. Cortez KJ, Roilides E, Quiroz-Telles F, Meletiadis J, Antachopoulos C, et al. (2008) Infections caused by Scedosporium spp. Clin Microbiol Rev 21: 157-197. [Crossref]

9. Mohr JA, Muchmore HG (1968) Susceptibility of Allescheria boydii to amphotericin B. Antimicrob Agents Chemother (Bethesda) 8: 429-430. [Crossref]

10. Travis LB, Roberts GD, Wilson WR (1985) Clinical significance of Pseudallescheria boydii: a review of 10 years' experience. Mayo Clin Proc 60: 531-537. [Crossref]

11. Gluckman SJ, Ries K, Abrutyn E (1977) Allescheria (Petriellidium) boydii sinusitis in a compromised host. J Clin Microbiol 5: 481-484. [Crossref]

12. Winston DJ, Jordan MC, Rhodes J (1977) Allescheria boydii infections in the immunosuppressed host. Am J Med 63: 830-835. [Crossref]

13. Hecht R, Montgomerie JZ (1978) Maxillary sinus infection with Allescheria boydii (Petriellidium boydii). Johns Hopkins Med J 142: 107-109. [Crossref]

14. Mader JT, Ream RS, Heath PW (1978) Petriellidium boydii (Allescheria boydii) sphenoidal sinusitis. JAMA 239: 2368-2369. [Crossref]

15. Bark CJ, Zaino LJ, Rossmiller K, Copper CL (1978) Petriellidium boydii sinusitis. JAMA 240: 1339-1340. [Crossref]

16. Bryan CS, DiSalvo AF, Kaufman L, Kaplan W, Brill AH, et al. (1980) Petriellidium boydii infection of the sphenoid sinus. Am J Clin Pathol 74: 846-851. [Crossref]

17. Bloom SM, Warner RR, Weitzman I (1982) Maxillary sinusitis: isolation of Scedosporium (Monosporium) apiospermum, anamorph of Petriellidium (Allescheria) boydii. Mt Sinai J Med 49: 492-494. [Crossref]

18. Winn RE, Ramsey PD, McDonald JC, Dunlop KJ (1983) Maxillary sinusitis from Pseudallescheria boydii. Efficacy of surgical therapy. Arch Otolaryngol 109: 123-125. [Crossref]

19. Schiess RJ, Coscia MF, McClellan GA (1984) Petriellidium boydii pachymeningitis treated with miconazole and ketoconazole. Neurosurgery 14: 220-224. [Crossref]

20. Morgan MA, Wilson WR, Neel HB 3rd, Roberts GD (1984) Fungal sinusitis in healthy and immunocompromised individuals. Am J Clin Pathol 82: 597-601. [Crossref]

21. Washburn RG, Kennedy DW, Begley MG, Henderson DK, Bennett JE (1988) Chronic fungal sinusitis in apparently normal hosts. Medicine (Baltimore) 67: 231-247. [Crossref]

22. Salitan ML, Lawson W, Sore PM, Bottone EJ, Biller HF (1990) Pseudallescheria sinusitis with intracranial extension in a nonimmunocompromised host. Otolaryngol Head Neck Surg 102: 745-750. [Crossref]
23. Terris DJ, Steiniger JR (1992) Scedosporium apiospermum: Fungal sinusitis in an immunocompetent patient. Am J Rhinol 6: 49-53.

24. Stamm MA, Frable MA (1992) Invasive sinusitis due to Pseudallescheria boydii in an immunocompetent host. South Med J 85: 439-441. [Crossref]

25. Watters GW, Milford CA (1993) Isolated sphenoid sinusitis due to Pseudallescheria boydii. J Laryngol Otol 107: 344-346. [Crossref]

26. Grigg AP, Phillips P, Durham S, Shepherd JD (1993) Recurrent Pseudallescheria boydii sinusitis in acute leukemia. Scand J Infect Dis 25: 263-267. [Crossref]

27. Meyer RD, Gaultier CR, Yamashita JT, Babapour R, Pitchon HE, et al. (1994) Funga sinusitis in patients with AIDS: report of 4 cases and review of the literature. Medicine (Baltimore) 73: 69-78. [Crossref]

28. Fiero RA, Groth M, Hurewitz A, April M, Nuovo M (1995) Chronic hemoptysis: an unusual manifestation of fungal sinusitis. South Med J 88: 782-785. [Crossref]

29. Machado CM, Martins MA, Heins-Vaccari EM, Lacaz Cda S, Macedo MC, et al. (1998) Scedosporium apiospermum sinusitis after bone marrow transplantation: report of a case. Rev Inst Med Trop Sao Paulo 40: 321-323. [Crossref]

30. Tadros TS, Workowski KA, Siegel RJ, Hunter S, Schwartz DA (1998) Pathology of hyalohyphomycosis caused by Scedosporium apiospermum (Pseudallescheria boydii): an emerging mycosis. Hum Pathol 29: 1266-1272. [Crossref]

31. Jones J, Katz SE, Lubow M (1999) Scedosporium apiospermum of the orbit. Arch Ophthalmol 117: 272-273. [Crossref]

32. Horton CK, Huang L, Goozé L (1999) Pseudallescheria boydii infection in AIDS. $J$ Acquir Immune Defic Syndr Hum Retrovirol 20: 209-211. [Crossref]

33. Shaw CL, McCleave M, Wormald PJ (2000) Unusual presentations of isolated sphenoid fungal sinusitis. J Laryngol Otol 114: 385-388. [Crossref]

34. Capilla J, Serena C, Pastor FJ, Ortoneda M, Guarro J (2003) Efficacy of voriconazole in treatment of systemic scedosporiosis in neutropenic mice. Antimicrob Agents Chemother 47: 3976-3978. [Crossref]

35. Apostolova L, Johnson E, Adams JP (2005) Disseminated Pseudallescheria boydi infection successfully treated with voriconazole. J Neurol Neurosurg Psychiatry 76 1741-1742. [Crossref]

36. John Hopkins antibiotic guidelines (2015-2016) Agent-specific guidelines. Antifungals. pp: 19-20

Copyright: C2017 Vaze V. This is an open-access article distributed under the terms of the Creative Commons Attribution License, which permits unrestricted use, distribution, and reproduction in any medium, provided the original author and source are credited. 